\title{
De Alma-Ata a Astana: o futuro, hoje
}

Armando Brito de Sá*

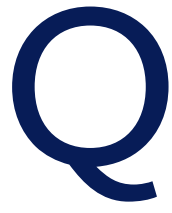

uarenta anos depois da declaração de Alma-Ata, ${ }^{1}$ uma das referências fundadoras dos cuidados de saúde primários tal como os concebemos hoje, a Organização Mundial da Saúde voltou ao Cazaquistão, em outubro de 2018, para refletir sobre a evolução dos cuidados de saúde primários e pensar nos caminhos a seguir a partir daqui. Por cá, poucos terão dado por isso: ao googlar a expressão "Conferência de Astana 2018» só aparecem sites brasileiros; quando juntamos a palavra «Portugal» identificam-se duas notícias de jornal (Just News e Tempo Medicina) e uma peça no site MGFamiliar, da autoria de Ana Barata, que esteve presente e participou no evento. ${ }^{2} \mathrm{Ou}$ seja, a conferência e a sua Declaração final ${ }^{3}$ terão essencialmente passado despercebidas.

Contudo, desta conferência terão saído das mais importantes reflexões em muito tempo sobre o que são os cuidados de saúde primários, qual o seu papel e para onde devem caminhar. A mensagem central é poderosa: "Estamos convencidos de que o reforço dos cuidados de saúde primários (CSP) constitui a abordagem mais inclusiva, efetiva e eficiente para melhorar a saúde física e mental das pessoas, e o seu bem-estar social, e de que os CSP são a pedra angular de um sistema de saúde sustentável para cobertura universal de cuidados de saúde e objetivos de desenvolvimento sustentado relacionados com a saúde" [tradução minha]. ${ }^{3}$

Desta mensagem retira-se, desde logo, uma ilação que entretanto foi analisada em pormenor: a relação direta entre CSP e cobertura universal de cuidados de saúde. ${ }^{4-5}$ A cobertura universal é uma característica procurada há muito na Europa e que é parte integrante da matriz conceptual do Serviço Nacional de Saúde português. Poder-se-ia, assim, considerar que estamos no caminho certo. As mensagens da Declaração de Astana, contudo, não se esgotam neste ponto. É chamada a atenção diretamente para "o crescimento das doenças

*Médico de família.USF Conde Saúde, ACeS da Arrábida. não transmissíveis que levam a menor saúde e mortes prematuras relacionadas com o tabaco, o uso nocivo do álcool, estilos de vida e comportamentos não saudáveis e insuficiente atividade física e alimentação não saudável” [tradução minha].

As recomendações finais centram-se na necessidade de acesso de todos a cuidados de promoção da saúde, prevenção, curativos, de reabilitação e paliativos. A pobreza extrema causada por despesas suplementares com a saúde tem de ser combatida. A promoção da saúde e prevenção da doença devem constituir prioridades e a fragmentação de cuidados deve ser combatida, tal como a falta de profissionais de saúde e a sua distribuição desigual nos territórios. O custo com os cuidados e o desperdício devem ser igualmente objeto de atenção.

Grande parte destas conclusões resultam de trabalho prévio realizado no âmbito da OMS e contido num documento preparatório da Conferência de Astana, que merece leitura atenta. ${ }^{6}$ Neste texto são identificadas as alterações contextuais ocorridas na Europa nos últimos quarenta anos, e que incluem (i) o envelhecimento da população, (ii) a escassez de recursos humanos agravada em vários países pela migração de profissionais para outros países, (iii) a alteração epidemiológica registada, com redução das infeções e problemas de saúde materna e infantil e aumento das doenças não transmissíveis, (iv) o agravamento dos determinantes sociais da saúde entre os mais desfavorecidos, (v) a alteração das expectativas sociais em relação à saúde e (vi) a crise económica global.

As soluções preconizadas neste relatório assentam nos cuidados centrados na pessoa, reforçando três áreas: inclusão, investimento e inovação. Em relação à última, vale a pena enumerar:

- Inovação na tomada de decisão e na responsabilização

- Inovação na gestão dos cuidados

- Inovação na inclusão das populações nos processos de decisão 
- Promoção da colaboração intersetorial

- Inovação no financiamento

- Inovação na obtenção de recursos e na sua gestão

- Inovação na prestação de cuidados

Entre os exemplos de sucesso dados (de Portugal apenas surge uma referência fugidia a novos modelos de pagamento dos cuidados a doenças crónicas) está a Holanda, cujos cuidados primários surgem como responsáveis por mais de $95 \%$ dos episódios de cuidados de saúde do país. Segundo é ainda citado, essa forte componente dos CSP holandeses seria responsável pela diminuição de cerca de um quarto da mortalidade evitável na Holanda. ${ }^{7}$

Em suma, de Astana vieram recomendações claríssimas sobre as áreas em que devemos concentrar os nossos esforços. Saiu ainda uma mensagem poderosa: teremos de sair das nossas áreas de conforto se queremos que o sistema de saúde evolua, sob risco de progressivamente passarmos à irrelevância.

Em entrevista à MEDI-COM de dezembro de 2018, merecedora de leitura atenta, ${ }^{8}$ Nadim Habib, da NOVA School of Business and Economics, reforça a inovação da organização dos cuidados de saúde como a solução para os problemas que nos afetam, e não apenas a injeção de mais recursos nos sistemas tal como os conhecemos hoje. Subscrevo a sua tese de que temos de repensar o SNS. Os documentos vindos de Astana indicam os problemas e apontam os caminhos. Cabe-nos a todos promover a mudança.

\section{REFERÊNCIAS BIBLIOGRÁFICAS}

1. World Health Organization. Declaration of Alma-Ata: international conference on primary health care, Alma-Ata, USSR, 6-12 September 1978 [Internet]. Geneva: WHO; 1978. Available from: https://www. who.int/publications/almaata_declaration_en.pdf

2. Barata AN. Global Conference on Primary Health Care 2018 [homepage]. MGFamiliar.net; 2018. Available from: https://www.mgfamiliar.net/_blog/MO/post/global-conference-on-primary-health-care2018/.

3. World Health Organization and the United Nations Children's Fund (UNICEF). Global conference on primary health care: from Alma-Ata towards universal health coverage and the Sustainable Development Goals, Astana, Kazakhstan, 25 and 26 October 2018 [Internet]. Geneva: WHO; 2018. Available from: https://www.who.int/docs/defaultsource/primary-health/declaration/gcphc-declaration.pdf

4. Kluge H, Kelley E, Barkley S, Theodorakis PN, Yamamoto N, Tsoy A, et al. How primary health care can make universal health coverage a reality, ensure healthy lives, and promote wellbeing for all. Lancet. 2018; 392(10156):1372-4.

5. Hill PS. Primary health care and universal health coverage: competing discourses? Lancet. 2018;392(10156):1374-5.

6. World Health Organization. From Alma-Ata to Astana: primary health care - reflecting on the past, transforming for the future [Internet]. Copenhagen: WHO Regional Office for Europe; 2018. Available from: https://www.who.int/docs/default-source/primary-health-care-conference/phc-regional-report-europe.pdf?sfvrsn=cf2badeb_2

7. Van Weel C, Schers H, Timmermans A. Health care in the Netherlands. J Am Board Fam Med. 2012;25 Suppl 1:S12-7.

8. Medi.com. Portugal precisa de criar um novo SNS. Medi.com. 2018; (218):20-3.

\section{ENDEREÇO PARA CORRESPONDÊNCIA}

E-mail: armando.sa@arslvt.min-saude.pt http://orcid.org/0000-0002-3900-4864 